\title{
Optimization of energy demand during ultrafiltration of cow's milk with different membranes
}

\author{
Siyka Kodinova ${ }^{1, *}$, and Mariya Dushkova ${ }^{1}$ \\ ${ }^{1}$ University of Food Technologies, Department of Process Engineering, Plovdiv, Bulgaria
}

\begin{abstract}
In this experimental work, the energy demand at different pressures $(0,2 \mathrm{MPa}$ and $0,5 \mathrm{MPa})$, the temperature $\left(20^{\circ} \mathrm{C}\right.$ and $\left.50{ }^{\circ} \mathrm{C}\right)$ and the cow's milk fat $(0,1 \%$ and $3,6 \%)$ during ultrafiltration by membranes with different membranes - $10 \mathrm{kDa}$ and $25 \mathrm{kDa}$, was investigated. The lower values of energy demand were established at lower pressure, fat and higher temperature. The greatest influence had the pressure for two membranes investigated, and the lowest - the fats for membrane $10 \mathrm{kDa}$ and the temperature for membrane $25 \mathrm{kDa}$, respectively. Membrane 10 $\mathrm{kDa}$ had higher energy demand than another membrane.
\end{abstract}

\section{Introduction}

The dairy industry is one of the largest energy consumers in the world. The optimization of energy demand can be achieved by the replacement of traditional energy-intensive unit thermal operations with some novel energy-efficient technologies and energy-efficiency practices [1,2]. The sustainable development of the dairies is related to the quality improvement, increased production and process efficiency, and to the reduction of energy consumption and production costs [3]. The environmental protection is a major issue for human health and economic evolution.

The dairy industry is one of the first sector which recognized the effective use of membrane processes, such as: ultrafiltration, nanofiltration, microfiltration and reverse osmosis. Ultrafiltration is a kind of membrane filtration in which forces like pressure or concentration gradients lead to a separation through a semi-permeable membrane. Suspended solids and solutes of high molecular weight are retained and they are well known as a retentate or concentrate, while water and low molecular weight solutes pass through the membrane in the permeate $[4,5,6]$. Membrane filtration, in particular ultrafiltration can be successfully used for separation, concentration and purification of milk components [7]. Its advantages compared to the classic separation methods are: environmental friendliness [8,9], lower power consumption [10], increased flow rate and quality of the product $[11,12]$, cost reduction [1], realization of the process at a low temperature in order to preserve heat-sensitive components [13]. It's important to know the effect of processing factors on the main characteristics of the process in order to control and

*Corresponding author: sisi.kozludjova@abv.bg 
manage it well. According to [14], the change of the pressure from $276 \mathrm{kPa}$ to $758 \mathrm{kPa}$ was insignificant in regard to the energy demand at ultrafiltration of skim milk. The energy demand was 2,3 times higher at temperature of $10{ }^{\circ} \mathrm{C}$ compared with $50{ }^{\circ} \mathrm{C}$. Similar effect of the temperature from $30{ }^{\circ} \mathrm{C}$ to $80{ }^{\circ} \mathrm{C}$ on the energy demand during ultrafiltration of alkali-extracted wheat bran hemicellulose was observed by [15]. They established that the lowest energy demand was $2,6 \mathrm{kWh} / \mathrm{m}^{3}$ at temperature of $80^{\circ} \mathrm{C}$ and cross flow velocity of $1 \mathrm{~m} / \mathrm{s}$ while at temperature of $30{ }^{\circ} \mathrm{C}$ and cross flow velocity of $7 \mathrm{~m} / \mathrm{s}$ the energy demand was $87 \mathrm{kWh} / \mathrm{m}^{3}$.

This work aimed to investigate the effect of pressure, temperature and fat content on the energy demand at ultrafiltration of cow's milk with different membranes.

\section{Materials and Methods}

\subsection{Materials}

\subsubsection{Cow's milk}

Two types of cow's milk were used for this investigation: a skim pasteurized milk with fat content of $0,1 \%$ and a standardized milk with fat content of 3,6\%. The milks were delivered by BCC Handel Ltd., Elena, Bulgaria.

\subsubsection{Ultrafiltration membranes}

Ultrafiltration membranes UF10-PAN and UF25-PAN produced from polyacrylonitrile were used. They had different molecular weight cut-off (10 kDa and $25 \mathrm{kDa})$.

\subsection{Methods}

\subsubsection{Ultrafiltration equipment}

The membrane filtration was carried out on a laboratory equipment, shown in Fig. 1. The working conditions, shown on Table 1, were established in previous our investigation [16].

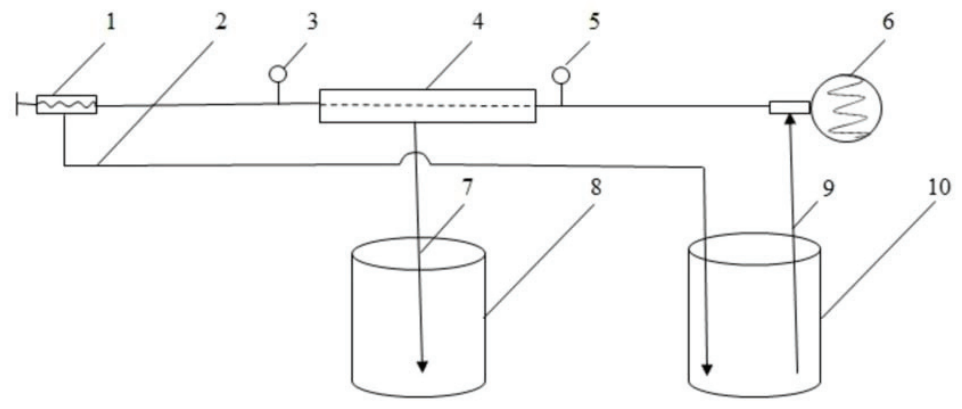

Fig. 1. Scheme of ultrafiltration system

1 - pressure regulator; 2 - pipeline for retentate; 3 - manometer (0 MPa to $1 \mathrm{MPa}) ; 4$ - replaceable plate and frame membrane module;5 - manometer (0 MPa to $1 \mathrm{MPa}) ; 6$ - 3-frame piston pump; 7 pipeline for permeate; 8 - tank for permeate; 9 - pipeline for feed solution/retentate; 10 - tank for feed solution/retentate. 


\subsubsection{Measurement of volumetric flux}

The volumetric flux $\left(\mathrm{J}, \mathrm{dm}^{3} /\left(\mathrm{m}^{2} . h\right)\right.$ was established by:

$$
J=V /(A . \tau)
$$

Where: $V$ was the permeate volume, $\mathrm{dm}^{3}$;

$A=0,125 \mathrm{~m}^{2}$ was the membrane area;

$\tau$ was the duration of the process, $\mathrm{h}$.

\subsubsection{Calculation of energy demand}

The power of the pump was calculated using equation (2) [17-19]:

$$
W_{\text {pump }}=\left(p_{1} \cdot Q_{\text {feed }}\right) / \eta_{\text {pump }}
$$

Where: $p_{I}$ was the pressure at the inlet of the system, Pa;

$Q_{\text {feed }}$ was the volumetric flow rate, $\left(\mathrm{m}^{3} / \mathrm{s}\right)$; the pump.

$\eta_{\text {pump }}=0,7$ was the pump efficiency according to [15,19], and type and state of

The energy demand per $\mathrm{m}^{3}$ of permeate was established [15]:

$$
E=W_{\text {pump }} /(J . A)
$$

Where: $J$ was the volumetric flux, $\mathrm{m}^{3} /\left(\mathrm{h}_{\mathrm{m}} \mathrm{m}^{2}\right)$;

$A$ was the membrane area, $\mathrm{m}^{2}$.

\subsubsection{Methods for statistical analyses}

The design of the experiments $\left(\mathrm{N}=2^{3}\right)$ for the influence of the pressure ( $\left.\mathrm{p}, \mathrm{MPa}\right)$, temperature $\left(\mathrm{T},{ }^{\circ} \mathrm{C}\right)$ and milk fat $(\mathrm{F}, \%)$ on the energy demand was presented on Table 1.

\begin{tabular}{|c|c|c|c|c|c|c|}
\hline \multirow{2}{*}{ № } & \multicolumn{3}{|c|}{ Natural values } & \multicolumn{3}{|c|}{ Coded values } \\
\hline & $\mathrm{p}, \mathrm{MPa}$ & $\mathrm{T},{ }^{\circ} \mathrm{C}$ & $\mathrm{F}, \%$ & $\mathrm{X}_{1}$ & $\mathrm{X}_{2}$ & $\mathrm{X}_{3}$ \\
\hline 1 & 0,2 & 20 & 0,1 & $-1,0$ & $-1,0$ & $-1,0$ \\
\hline 2 & 0,5 & 20 & 0,1 & 1,0 & $-1,0$ & $-1,0$ \\
\hline 3 & 0,2 & 50 & 0,1 & $-1,0$ & 1,0 & $-1,0$ \\
\hline 4 & 0,5 & 50 & 0,1 & 1,0 & 1,0 & $-1,0$ \\
\hline 5 & 0,2 & 20 & 3,6 & $-1,0$ & $-1,0$ & 1,0 \\
\hline 6 & 0,5 & 20 & 3,6 & 1,0 & $-1,0$ & 1,0 \\
\hline 7 & 0,2 & 50 & 3,6 & $-1,0$ & 1,0 & 1,0 \\
\hline 8 & 0,5 & 50 & 3,6 & 1,0 & 1,0 & 1,0 \\
\hline
\end{tabular}
Three repetitions at each point were made.

Table 1. Design of the experiments

StatGraph XIV trial version software was used to obtain regression models. 


\section{Results and Discussion}

The averages of the energy demand were shown on Table 2. They changed from 15,37 $\mathrm{kWh} / \mathrm{m}^{3}$ to $46,87 \mathrm{kWh} / \mathrm{m}^{3}$ for UF10-PAN membrane and from $9,36 \mathrm{kWh} / \mathrm{m}^{3}$ to 40,89 $\mathrm{kWh} / \mathrm{m}^{3}$ for UF25-PAN membrane.

Table 2. Effect of the factors on the energy demand

\begin{tabular}{||c|c|c|c|c|c||}
\hline \hline & & & & \multicolumn{2}{|c||}{ Energy demand, $\mathrm{kWh} / \mathrm{m}^{3}$} \\
\cline { 5 - 6 } № & \multirow{2}{*}{$\mathrm{p}, \mathrm{MPa}$} & $\mathrm{T},{ }^{\circ} \mathrm{C}$ & $\mathrm{F}, \%$ & \multicolumn{2}{|c||}{} \\
\cline { 5 - 7 } & & & & UF10-PAN & UF25-PAN \\
\hline 1 & 0,2 & 20 & 0,1 & $20,12 \pm 0,93$ & $12,13 \pm 0,23$ \\
\hline 2 & 0,5 & 20 & 0,1 & $41,38 \pm 0,37$ & $24,36 \pm 0,34$ \\
\hline 3 & 0,2 & 50 & 0,1 & $15,37 \pm 0,23$ & $9,36 \pm 0,47$ \\
\hline 4 & 0,5 & 50 & 0,1 & $32,83 \pm 1,30$ & $20,64 \pm 0,28$ \\
\hline 5 & 0,2 & 20 & 3,6 & $21,61 \pm 0,65$ & $19,28 \pm 0,48$ \\
\hline 6 & 0,5 & 20 & 3,6 & $46,87 \pm 0,77$ & $40,89 \pm 0,69$ \\
\hline 7 & 0,2 & 50 & 3,6 & $18,29 \pm 0,17$ & $15,78 \pm 0,35$ \\
\hline 8 & 0,5 & 50 & 3,6 & $41,34 \pm 1,32$ & $32,19 \pm 0,49$ \\
\hline
\end{tabular}

Adequate models (equation 4 for UF10-PAN, equation 5 for UF25-PAN) with significant coefficients $(\alpha=0,95)$ were obtained:

Energy demand $=29,7267+10,8775 \cdot X_{1}-2,76833 \cdot X_{2}+2,30167 \cdot X_{3}-0,749167 \cdot X_{1} \cdot X_{2}+$ $1,1975 \cdot X_{1} \cdot X_{3}+0,556667 X_{2} \cdot X_{3}$

$$
\mathrm{R}^{2}=99,9 \% \quad \mathrm{~F}=1,68<\mathrm{F}_{\mathrm{T}}=4,5
$$

Energy demand $=21,83+7,6925 \cdot X_{1}-2,33583 \cdot X_{2}+5,20833 \cdot X_{3}-0,768333 \cdot X_{1} \cdot X_{2}+$ 1,81417.X1.X $\mathrm{X}_{3} F-0,714167 \cdot X_{2} \cdot X_{3}$

$$
\mathrm{R}^{2}=99,7 \% \mathrm{~F}=2,90<\mathrm{F}_{\mathrm{T}}=4,5
$$

Figure 2 demonstrated the significance of all factors and interactions between them. The increase in the pressure and the fat content, and the decrease in the temperature led to a rise in the energy demand. When UF10-PAN membrane was used, the pressure had the highest effect, then the temperature and the fat content. During ultrafiltration with UF25-PAN membrane, the fat content had more pronounced effect than the temperature (Fig. 3). The difference of the effect of the temperature on the energy demand for both membranes could be explained by the certain that the temperature had more pronounced influence on the flux when UF25-PAN was used. This was probably due to the higher molecular weight cut-off of this membrane compared with UF10-PAN.
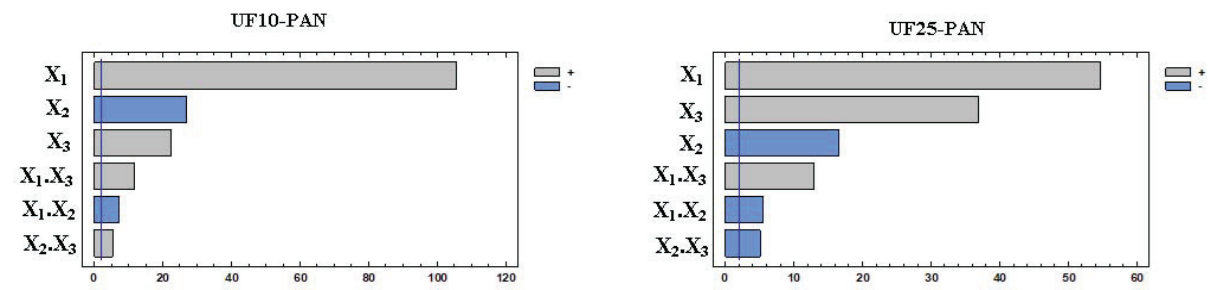

Fig. 2. Standardized charts of Pareto 

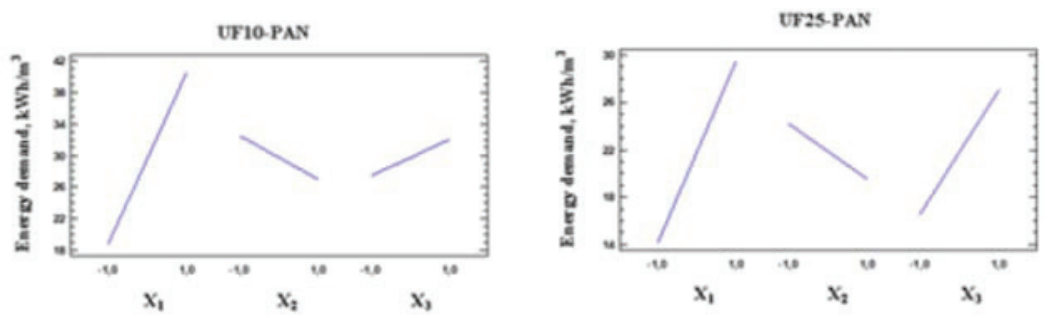

Fig. 3. Single effect of the studied factors on the energy demand

The combined effect of the pressure $\left(\mathrm{X}_{1}\right)$, temperature $\left(\mathrm{X}_{2}\right)$ and milk fat $\left(\mathrm{X}_{3}\right)$ on the energy demand was presented in Fig. 4. The influence of the above-mentioned factors had the same tendency for both membranes. The values of the energy demand were higher when an UF10-PAN membrane was used. According to [14], the energy demand was higher at a temperature of $10{ }^{\circ} \mathrm{C}$ compared with $50{ }^{\circ} \mathrm{C}$ during ultrafiltration of skim milk. The authors also proved that the optimal energy efficiency was achieved when the ultrafiltration was operated at a high temperature and a low pressure. Some authors [15] found that the energy demand decreased when the temperature increased from $30^{\circ} \mathrm{C}$ to 80 ${ }^{\circ} \mathrm{C}$. The viscosity decreased when the temperature increased which favored the passage of the molecules through the membrane. Therefore, the energy demand decreased. The rise in the pressure led to a higher power of the pump and energy demand, respectively.
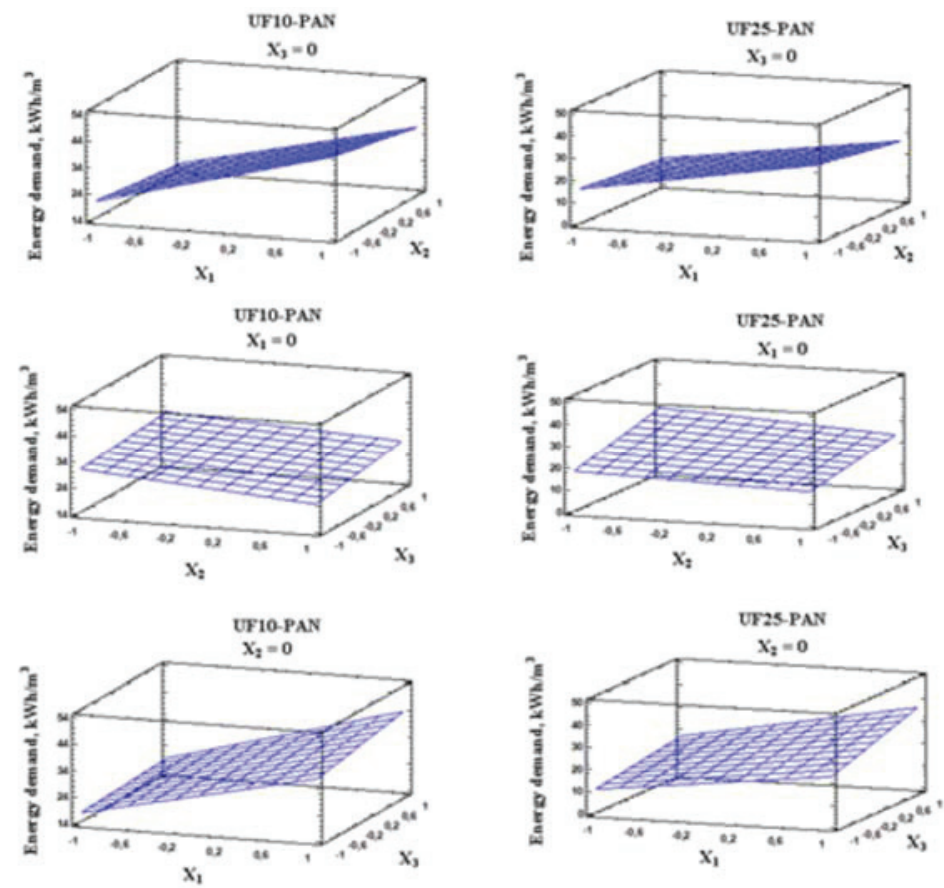

Fig. 4. Effect of the working pressure $\left(X_{1}\right)$, the temperature $\left(X_{2}\right)$ and the milk fat content $\left(X_{3}\right)$ on the energy demand

The optimization of the energy demand depending on the factors for UF10-PAN and UF25-PAN (Table 3 ) indicated that the optimum (the lowest) value was achieved at $\mathrm{p}=0,2$ $\mathrm{MPa}, \mathrm{F}=0,1 \%$ and $\mathrm{T}=50{ }^{\circ} \mathrm{C}$. The comparison of the membranes showed that the 
optimum energy demand was $15,37 \mathrm{kWh} / \mathrm{m}^{3}$ for UF10-PAN membrane and $9,36 \mathrm{kWh} / \mathrm{m}^{3}$ for UF25-PAN membrane, respectively.

Table 3. Optimization of the energy demand depending on the investigated factors for UF10-PAN and UF25-PAN membranes

\begin{tabular}{|c|c|c|c|}
\hline Factor & Low & High & Optimum value \\
\hline $\mathrm{X}_{1}$ & $-1,0$ & 1,0 & $-1,0$ \\
\hline $\mathrm{X}_{2}$ & $-1,0$ & 1,0 & 1,0 \\
\hline $\mathrm{X}_{3}$ & $-1,0$ & 1,0 & $-1,0$ \\
\hline
\end{tabular}

Note: The optimum meant the lowest value of energy demand.

\section{Conclusions}

Energy consumption is one of the main economical indices of each industrial sector. The optimization of the energy demand, depending on various process factors, leads to a decrease in the product cost. There are not enough literature data about the influence of working conditions on the energy demand during ultrafiltration of milk. The results from our experimental work demonstrated a lower energy demand when the working pressure and fat content decreased while the temperature increased for both membranes investigated. The comparison of the results showed that lower energy demand was established for UF25PAN membrane than for UF10-PAN membrane. The lowest energy demand was 9,36 $\mathrm{kWh} / \mathrm{m}^{3}$ for UF25-PAN and $15,37 \mathrm{kWh} / \mathrm{m}^{3}$ for UF10-PAN. For all these reasons, we recommend to work at low pressure, fat content and high temperature.

\section{References}

1. A. Kalla, K.N. Krishna, R. Devaraju, Int. J. Appl. Eng. Res. Dev. 7, 1 (2017)

2. C.A. Ramírez, M. Patel, K. Blok, Energy 31, 1984 (2006)

3. L. Wang, Energ. Effic. 7, 791 (2014)

4. M. Corredig, P.K. Nair, Y. Li, H. Eshpari, Z. Zhao, J. Dairy Sci. 102, 4772 (2019)

5. V. Dhineshkumar, D. Ramasamy, J. Appl. Biotechnol. Bioeng. 3, 399 (2017)

6. M. Jahadi, M. Ehsani, S. Paidari, J. Food Biosci. Technol. 8, 49 (2018)

7. G.Q. Chen, T.S. H. Leong, S.E. Kentish, M. Ashokkumar, G.J. O. Martin, Separation of Functional Molecules in Food by Membrane Technology (Academic Press LtdElsevier Science Ltd, USA, 2019)

8. P. Kumar, N. Sharma, R. Ranjan, S. Kumar, Z. Bhat, D. Jeong, Asian-Australas J. Anim. Sci. 26, 1347 (2013)

9. A. Tamime, Membrane Processing - Dairy and Beverage Applications (WileyBlackwell, New York, 2013)

10. C. Baldasso, T. Barros, I. Tessaro, Desalination 278, 381 (2011)

11. A. Macedo, E. Duarte, M. Pinho, J. Membr. Sci. 381, 34 (2011)

12. L. Ong, R. Dagastine, S. Kentish, S. Gras, Foods 2, 310 (2013)

13. P. Kelly, Encyclopedia of Dairy Science (Mississippi State University, USA, 2011)

14. S. Méthot-Hains, S. Benoit, C. Bouchard, A. Doyen, L. Bazinet, Y. Pouliot, J. Dairy Sci. 99, 8655 (2016)

15. J. Thuvander, A. Arkell, A-S. Jönsson, Chemical Eng. Res. Design 138, 43 (2018)

16. S. Kozludzhova, M. Dushkova, K. Dinkov, M. Miteva, Food Ind. 5, 25 (2015)

17. M. Mercier, C. Fonade, C. Lafforgue-Delorme, J. Membr. Sci. 128, 103 (1997)

18. S. Laborie, C. Cabassud, L. Durand-Bourlier, J.M. Laine, Desalination 118, 189 (1998)

19. J.Q. Verberk, J.C. Van Dijk, J. Membr. Sci. 284, 339 (2006) 